\title{
ARSITEKTUR KHAS BUDAYA MAKAM TIPE MANDAR DI SITUS KOMPLEKS MAKAM LOMBENG SUSU MAJENE SULAWESI BARAT
}

\section{TYPICAL ARCHITECTURAL CULTURE OF THE TYPES MANDAR GRAVE IN THE COMPLEX LOMBENG SUSU MAMUJU WEST SULAWESI}

\author{
Rosmawati \\ Fakultas Ilmu Budaya, Universitas Hasanuddin \\ Makassar, Sulawesi Selatan \\ Jl.Perintis Kemerdekaan Kampus Tamalanrea \\ Email: rosmawati_57@yahoo.co.id
}

Naskah diterima tanggal 10 Agustus 2016. Naskah direvisi tanggal 21 September 2016. Naskah disetujui tanggal 9 November 2016

\begin{abstract}
Abstrak
Kawasan Majene sangat kaya dengan tinggalan budaya Islam, salah satunya adalah makam-makam kuno yang tersebar luas di daerah tersebut. Sebaran makam-makam kuno tersebut belum banyak diteliti dan dikaji secara ilmiah, sehingga tidak banyak yang diketahui dan difahami mngenai bentuk dan kandungan makna budaya yang terdapat pada makam-makam tersebut. Untuk itu, maka dalam tulisan ini akan dibuat tipologi jirat dan nisan makam yang terdapat di wilayah tersebut, dengan tujuan untuk dapat mengetahui tipe makam yang khas berkembang di daerah tersebut. Metode yang digunakan dalam penelitian ini adalah studi kajian pustaka untuk menyusun kerangka konseptual berupa gagasan, hipotesis atau teori; sebagai petunjuk awal di dalam mencari dan memahami data lapangan, terutama untuk mengetahui situs-situs yang akan disurvei dalam pengumpulan data lapangan; untuk mengetahui isu dan masalah yang wujud dalam kajian Zaman Islam di Sulawesi Barat. Pengumpulan data dari dua sumber, yaitu data arkeologi sebagai data primer dan data sejarah berupa tulisan sejarah maupun kronik lontaraq yang ada hubungannya dengan topik penelitian sebagai data sekunder. Hasil kajian ini menunjukkan bahwa tipe khas makam Mandar, dapat dilihat pada peninggalan makam-makam kuno di kawasan Majene, yaitu jirat berteras lurus dengan konstruksi tiang pada keempat sudut jirat, nisan hulu badik, nisan mahkota, nisan pedang bertangkai dan bahan makam dibuat dari pada batu karang.
\end{abstract}

Kata Kunci: kuburan, makam, nisan, budaya, Islam

\begin{abstract}
Majene district is rich with the remains of Islamic culture, one of which is the ancient grave and widely scattered in the area. The distribution of ancient tombs have not been much studied scientifically, so not much is known about the form and content of cultural meaning contained in these tombs. The concept of social stratification still clearly visible applied to the tombs of the kings in some tomb complex in Majene district, such as the difference in the tomb, headstone tomb and how many ancient grave sites. Therefore, in this paper will be made typology tomb and headstone tomb found in the area that, in order to determine the type of tomb typical flourish in the area. The method used in this research is the study reviewed the literature to draw up conceptual frameworks in the form of ideas, hypotheses or theories; represent an early stage in the search for and understand the data field, especially to determine the sites to be surveyed in the field data collection; to know the issues and problems that form in the study of the Age of Islam in West Sulawesi. Collecting data from two sources, namely the archaeological data as the primary data and the historical data in the form of historical writing or chronic lontaraq that has to do with the research topic as secondary data. The results of these studies show that the typical type tomb Mandar, can be shown by the ancient tombs in the area of Majene, the tomb terraced straight pole construction on the four corners of the tomb, gravestone upstream dagger, headstone crown, headstone sword stemmed and materials tomb is made of the Coral reef.
\end{abstract}

Keywords: grave, tomb, gravestone, culture, Islam 


\section{PENDAHULUAN}

$\mathrm{K}$ ajian mengenai perkembangan agama Islam selalu menjadi perhatian oleh para sarjana sejak awal hingga sekarang. Berbagai masalah yang tercakup di dalam sejarah Islam tetap aktual dalam wacana kesejarahan. Ada tiga persoalan utama yang selalu menjadi bahan kajian para sarjana yang tidak pernah berakhir untuk dibahas, yaitu hal yang berhubungan dengan pertanyaan berasal dari mana, dibawa oleh siapa dan kapan masa Islam masuk dan berkembang di suatu kawasan di Nusantara. Olehnya itu, dalam kajian ini akan menjelaskan ketiga persoalan tersebut, khususnya di kawasan Sulawesi Selatan berdasarkan data sejarah dan arkeologi.

Salah satu tinggalan arkeologi pada masa awal Islam yang banyak ditemukan di Majene adalah makam para raja-raja, pemuka agama dan adipati (penguasa daerah). Pada umumnya makam ini merupakan suatu kompleks pemakaman yang di dalamnya terdapat keluarga atau kerabat, para aparat atau pembesar kerajaan dan para pengikut. Keberadaan makam-makam tersebut, merupakan bukti awal masuknya agama Islam di kawasan Sulawesi Barat.

Sejauh yang diketahui ada dua kerajaan di wilayah Mandar yang mula dimasuki oleh penganjur agama Islam, yaitu Kerajaan Balanipa dan Kerajaan Pamboang. Kerajaan Balanipa adalah kawasan Mandar yang terletak di bagian selatan dan kerajaan Pamboang merupakan kawasan Mandar yang ada di bagian utara. Kawasan bagian selatan meliputi Polewali-Mamasa dan sebagian kawasan Majene, kawasan bagian utara meliputi kawasan Kabupaten Majene dan seluruh kawasan Kabupaten Mamuju dan Mamauju Utara sekarang.

Jika dilihat dari segi letak geografi, kedua kawasan daerah ini sangat memungkinkan untuk dikunjungi atau didatangi oleh penganjur agama Islam pada masa lampau. Kedua kerajaan di kawasan tersebut mempunyai pelabuhan yang banyak dikunjungi para pedagang lewat jalur laut. Meskipun demikian, hingga sekarang ini masih terdapat perbedaan pandangan tentang siapa, kapan dari mana asal pembawa pertama agama Islam ke kedua kerajaan tersebut. Ada tiga versi tentang asal-usul dan pembawa agama Islam ke kawasan tersebut, yaitu: (1) agama Islam mulamula masuk dan diterima oleh masyarakat di kawasan Mandar, dibawa oleh Tuanta Yusuf (Syekh Yusuf), yang dikenal dengan gelar Tuanta Salamaka
Tajul Khalawati pada abad XVI M (Sewang, 1980: 31). (2) Agama Islam di kawasan Mandar dibawa oleh Raden Mas Suryodilogo dan Syekh Zakaria Al Maghribi pada akhir abad XVI M. Kedua penganjur agama Islam ini langsung dari pulau Jawa, dan daerah yang pertama didatangi ialah Kerajaan Pamboang. Hal ini disebabkan karena Pamboang sejak zaman dahulu dikenal sebagai salah satu bandar perdagangan di daerah Mandar, dan berdasarkan arus angin dan letak geografi, Pamboang merupakan tempat penentuan arah pelayaran bagi pelaut yang mendiami bagian timur daerah Mandar untuk berlayar ke pulau Jawa dan Kalimantan. Secara geografi, Pamboang lebih dekat kepada kedua kawasan tersebut (Sewang, 1980: 32). (3) Agama Islam masuk ke Tanah Mandar, terlebih dahulu masuk ke kawasan Kerajaan Balanipa di bagian selatan kawasan Mandar. Menurut Lontaraq I Balanipa, mengatakan bahwa pembawa agama Islam ke daerah Mandar bukan Syekh Yusuf, melainkan seorang ulama yang bernama Abdurrahim Kamaluddin, yaitu pada masa pemerintahan raja Kerajaan Balanipa yang keempat, yaitu Kakanna I Pattang Daetta Tommuane.

Pada situs-situs makam kuno di kawasan Majene separti di Kompleks Makam Lombengsusu, ditemukan adanya bentuk makam yang khas bila dibandingkan dengan makam-makam lainnya di Indonesia. Kekhasan tersebut tampak pada jirat, nisan, ornamen dan bahan yang digunakan. Berdasarkan pada fenomena tersebut, maka penulis kemudian mencoba untuk menjelaskan bagaimana tipologi jirat dan nisan makam di Majene, khususnya pada Kompleks Makam Lombengsusu, sebagai tipologi khas makam-makam kuno pada masyarakat Mandar. Hal dirasakan sangat penting untuk dilakukan, karena belum pernah ada penelitian terhadap situs tersebut. Penelitian ini bertujuan untuk membuat deskripsi yang akan menjadi patokan dalam melakukan kajian yang lebih mendalam pada budaya Mandar di masa yang akan datang.

\section{METODE PENELITIAN}

Pada tahap awal penelitian ini, penulis melakukan studi/kajian pustaka, yaitu dengan mengkaji sejumlah buku-buku, jurnal, laporanlaporan dan tulisan-tulisan yang lain untuk mendapatkan informasi awal yang ada hubungannya dengan topik penelitian. Pengumpulan data pustaka bertujuan untuk: (1) menyusun kerangka konseptual berupa gagasan, hipotesis atau teori; (2) sebagai petunjuk awal dalam mencari dan memahami 
data lapangan, terutama untuk mengetahui situssitus yang akan disurvei dalam pengumpulan data lapangan; (3) untuk mengetahui isu dan masalah yang wujud dalam kajian Zaman Islam di Sulawesi Barat.

Selanjutnya penelitian ini mengumpulkan data dari dua sumber, yaitu data arkeologi sebagai data primer dan data sejarah berupa tulisan sejarah maupun kronik lontaraq yang ada hubungannya dengan topik penelitian sebagai data sekunder.

\section{PEMBAHASAN}

\section{Latar Belakang Sejarah}

Kerajaan Litaq Mandar adalah gabungan dua kelompok federasi Pitu Ulunna Salu (tujuh hulu sungai) yang terdiri dari Aralle, Mambi, Bambang, Rante Puluhan atau Rante Buluhan, Matangnga, Tandong, dan Tu'bi serta kelompok federasi Pitu Babanna Binanga (tujuh hilir sungai) yang terdiri dari Balanipa, Sendana, Banggae, Pamboang, Tappalang, Mamuju, dan Binuang. Terbentuknya kedua federasi tersebut tidak menunjukkan angka tahun yang pasti, tetapi diduga kuat terbentuk sekitar abad ke-5 hingga abad ke-6M (Poelinggomang et al, 2004: 41). Persekutuan Pitu Ulunna Salu terbentuk atas prakarsa Londang Dehata atau To Mampu dari Rante Bulahan dan Puang Banua dari Aralle yang mampu mempertahankan Tabulahan dan mengusir pasukan-pasukan Tinata dan Lohe dari wilayah pegunungan Mandar. Apalagi Tabulahan diyakini sebagai tempat penyebaran nenek moyang suku Mandar yaitu Pongkapadang dan Torijene sehingga terbentuklah persekutuan Pitu Ulunna Salu yang diserahi tugas masing-masing setiap anggota. Mengenai federasi Pitu Babanna Binanga, terbentuk atas prakarsa Tomapayung Raja II Kerajaan Balanipa, persekutuan dari Appe Banua Kaiyang (empat negeri) yaitu: Napo, Samasundu, Masso dan Todang-Todang.

Hal ini dijalankan untuk melanjutkan citacita orang tuanya Manyambungi Todilaling sebagai Mara'dia atau Raja I Balanipa. Federasi ini terbentuk karena adanya kezaliman dan kesewenangwenangan dari penguasa pasukan Pasokkorang, yang mendapat perlindungan dari Pitu Ulunna Salu akibat adanya perbedaan pandangan rancangan mendasar terhadap konsep norma yang diyakini antara Pitu Ulunna Salu dengan Pitu Babana Binanga. Untuk mengatasi hal itu, maka diadakanlah pertemuan yang dihadiri oleh enam kerajaan kawasan pesisir pantai di puncak gunung Tamajarro. Pertemuan ini melahirkan persekutuan kekeluargaan yang melahirkan federasi Pitu Babanna Binanga yang disebut Perjanjian Tamajarro.Persatuan Lita Mandar dapat dicapai dengan mengatasi perselisihan berkepanjangan antara Pitu Ulunna Salu dengan Pitu Babana Binanga. Diadakanlah pertemuan di kawasan Luyo, yaitu perbatasan antara kedua federasi tersebut, yang diprakarsai oleh To Mepayung Maradia Balanipa II dan Londang Deata To Mampu, To Makaka Rante Buluhan, dan dihadiri oleh semua kelompok kerajaan yang berada di kawasan Mandar. Pertemuan ini menghasilkan perjanjian Luyo yang disebut Allamungeng Batu di Luyo (Poelinggomang et al, 2004: 41-42).

Di kawasan Pitu Babana Binanga terdapat dua kerajaan yang menonjol dan berpengaruh, yaitu Kerajaan Balanipa dan Kerajaan Pamboang. Kerajaan Balanipa adalah kawasan Mandar yang terletak di bagian selatan dan kerajaan Pamboang merupakan kawasan Mandar yang ada di bagian utara. Kawasan bagian selatan meliputi PolewaliMamasa dan sebagian kawasan Majene, kawasan bagian utara meliputi kawasan Kabupaten Majene dan seluruh kawasan Kabupaten Mamuju dan Mamuju Utara sekarang.

Dikisahkan, bahwa jauh sebelum agama Islam masuk di Mandar, telah ada seorang pendatang yang berasal dari suatu daerah yang sangat jauh, yang letaknya searah dengan arah terbitnya matahari (Polea karao, pole dimata allo). Di dalam Lontaraq Mandar (kutipan dari Lontaraq Banggae, Itoa), pendatang tersebut disebut sebagai To Pole-pole. Pendatang ini pertamakali tiba di Barane (sekarang Kampung Pangale) dan kemudian meneruskan perjalanannya ke Kampung Lipu, dengan diiringi beberapa pengawal dan penasehat. Setibanya di kampung Lipu, To Pole-pole bertemu dengan orangorang yang berasal dari Mawasa, yaitu suatu daerah yang letaknya berada di sekitar Kampung Lipu. Selanjutnya dari hasil pemberitahuan masyarakat atau orang-orang tadi, To Makaka di Mawasa menemui pendatang tersebut (To Pole-pole, yang menurut kisah adalah seorang yang memiliki pengetahuan dan kepandaian sangat tinggi). Oleh To Makaka, memberikan penempatan sebagai situs tinggal menetap bagi To Pole-pole, yaitu di Lipu (tempat pertama tiba).

Hubungan kuasa antara To Makaka dengan To Pole-pole adalah diibaratkan sebagai daun yang berhembuskan angin (irimo-o mudaung aju), yang bermakna bersatu padu dalam kuasa dan kekuasaan 
di Mawasa. Landasannya ditetapkan ketentuan bahwa segala sesuatu yang akan dilakukan harus berdasarkan musyawarah di antara To Makaka Mawasa dengan To Pole-pole. Setelah To Polepole berdiam di Mawasa, barulah diberitahukan oleh To Makaka di Mawasa, bahwa sesungguhnya Mawasa merupakan daerah yang berada dalam kekuasaan To Makaka di Poralle (Salobose). Dari pemberitahuan tersebut timbul minat To Pole-pole untuk melawat ke Poralle di Salobose. To Polepole diterima baik oleh raja Kerajaan Salabose, bahkan karena kepandaiaannya dalam pelbagai hal, maka dia dinikahkan dengan putri raja yang cantik jelita, bernama To Meruppa-rupa Bulawang. Setelah perkawinannya tersebut, maka To Pole-pole diberikan kawasan situs tinggal di Ujung (kawasan yang sering didatangi oleh musuh kerajaan). Untuk menjamin kekuatannya, maka dibangunlah pagar di seluruh kawasan Ujung dan sekitarnya termasuk lingkungan Banggae, sehingga keamanan tempat kediaman To Pole-pole dan To Merrupa-rupa Bulawang selaku suami istri lebih terjamin (Duli et al, 2014).

Setelah lama berselang beberapa masa menetap di daerah Poralle, maka dipersatukanlah kawasan Mawasa dengan Poralle. Hasil perkawinan melahirkan dua orang anak, anak pertama tidak diketahui namanya dan anak yang kedua bernama Daenta di Poralle, yang kemudian menjadi raja pertama (Mara'dia I) dari Kerajaan Banggae. Rajaraja Kerajaan Banggae selanjutnya berasal dari keturunan raja berkenaan. Anak pertama dari To Pole-pole, tinggal di kawasan Ujung. Beliau diriwayatkan beristri dua, masing-masing To Makaka Dinaong Indu dan To Makaka di Mawasa, yang masing-masing memiliki anak bernama I Puang Dinaong Indu (Mabicara di Banggae dan Totoli) berasal dari To Makaka Dinaong Indu, sedangkan I Puang Anning (To Kaiyang di Banggae) berasal dari To Makaka Di Mawasa.

Anak yang kedua, yaitu Daenta Poralle, diriwayatkan menuju Balanipa dan kawin dengan anak dari Tomepayung Balanipa, dan dari hasil perkawinan tersebut, dikaruniai empat (4) orang anak, yaitu: Daenta di Tali, Daenta di Malanto, Daenta di Puja dan Daenta di Balibaru. Dalam pemerintahan selanjutnya, Daenta Malanto menjadi raja (Mara'dia II) di Kerajaan Banggae. Daenta Malanto memperisterikan To Peannani Daenta di Masigi Totoli, dan dari hasil perkawinannya melahirkan anak bernama Daenta di Masigi yang kemudian menjadi raja (Mara'dia III) di Kerajaan
Banggae. Dia dikaruniai empat (4) orang anak, dan seorang anaknya yaitu, To Matindo di Weboro kemudian menjadi Raja (Mara'dia VI) Kerajaan Banggae, dan saudaranya To Matindo di Salombo menjadi raja Kerajaan Banggae (Mara'dia V). Seorang saudaranya lagi yaitu, Topeanani Toniboseng menjadi raja Kerajaan Banggae (Maradia VI). Demikianlah seterusnya turunan dari raja-raja Banggae, menjadi raja (Mara'dia), hingga raja XIII dan XIV.

Kerajaan Banggae tidak terlepas dari asal mula berdirinya kerajaan-kerajaan lainnya, bahwa seseorang yang diangkat menjadi raja biasanya adalah selain dari keturunan bangsawan, juga orang yang arif dan bijakasana, pandai, memiliki kemampuan yang luar biasa serta perkasa. Demikian halnya dengan raja-raja Kerajaan Banggae, yang memimpin rakyatnya dengan segala kelebihan yang dimilikinya, sehingga memberikan rasa cinta dan ketaatan rakyat terhadap rajanya. Dikisahkan, oleh karena kecintaan rakyat terhadap rajanya, maka sewaktu raja mangkat, banyak pengikutnya yang rela mengorbankan jiwa, raga dan harta bendanya untuk ikut dimakamkan bersama-sama dengan rajanya. Selain itu juga dikisahkan bahwa dalam pemakaman raja, juga dikuburkan bersama seperangkat harta benda kerajaan beserta dayang-dayangnya. Mayat dikuburkan ke dalam tanah, di atasnya ditancapkan batu tegak (menhir) sebagai tanda, atau dibuatkan tumpukan batu seperti bentuk gunungan atau teras, terutama bagi para bangsawan atau orang berpengaruh. Untuk orang biasa, kuburnya hanya ditandai dengan ditanamkan pohon di atasnya atau ganya berupa tumpukan batu sederhana. Hal ini berlangsung terus hingga raja Kerajaan Banggae (Mara'dia III) yang belum menganut agama Islam, sedangkan untuk raja Kerajaan Banggae (Maradia IV) dan seterusnya, agama Islam telah masuk dan berpengaruh dengan sangat ketat di dalam sistem pemerintahan kerajaan, sehingga pemakaman serupa seperti yang dijalankan untuk Raja Banggae (Mara'dia I, II, III) tidak lagi dijalankan, melainkan disesuaikan denga sistem pemakaman Islam (Duli et al, 2014).

Sumber Lontaraq Mandar menjelaskan tentang peranan orang Mandar dalam pelbagai pelayaran ke kawasan-kawasan lainnya di Nusantara, adalah bahwa masyarakat Pamboang (Mandar) sudah dikenal sejak awal sebagai pelaut yang berani berlayar dan mengarungi laut lepas di seluruh kawasan perairan Nusantara. Mereka berlayar 
ke Sumatera, Jawa, Kalimantan, Maluku, Irian dan kawasan yang lain. Bukan hanya masyarakat Pamboang dikenal di kawasan Mandar sebagai pelaut, tetapi pada umumnya semua orang Mandar terkenal sebagai pelayar, bahkan orang-orang Mandar sejak dahulu kala terkenal sebagai pelaut ulung di Sulawesi, mereka mengadakan banyak pelayaran dan lalu lintas laut dengan perahu-perahu khas mereka (Hamsah, 1976: 27). Pelayaran orang Mandar ke Pulau Jawa, biasanya menuju ke Gresik dan Tuban, mereka berangkat di waktu musim kemarau dan diperkirakan pada musim hujan mereka pun kembali ke Pamboang. Jika berlayar ke Jawa dengan tiupan angin timur, biasanya mereka hanya menempuh perjalanan selama satu minggu. Gresik dan Tuban merupakan situs pelabuhan di bagian utara Jawa Timur yang selalu disinggahi oleh para pedagang-pedagang. Gresik dan Tuban semakin terkenal dan ramai dikunjungi pedagangpedagang sejak berdirinya kerajaan Islam di Jawa Timur. Karena itu kedua kota di Jawa Timur ini kemudian dijadikan sebagai pusat kegiatan pengiriman muballig-muballig Islam ke luar pulau Jawa oleh penganjur-penganjur Islam.

Dalam Lontaraq Mandar dijelaskan bahwa dari Tubanlah para muballig Islam menyebar ke Maluku, ke Sulawesi, dan juga ke Kalimantan. Konon muballig-muballig dari Aceh dan Malaka (Malaysia) juga ikut meramaikan jalannya dakwah melalui bandar Gresik dan Tuban (Zuhri, 1979: 391). Bagi pelaut Pamboang yang memudahkan mereka dalam mengarungi laut luas sampai ke Jawa adalah semangat keberanian, terutama dengan bantuan arus angin timur yang bertiup antara bulan Mei hingga September. Karena itu, setiap mereka melakukan pelayaran ke pulau Jawa, selamanya dimulai pada waktu datangnya musim kemarau.

Legenda pembawa agama Islam dari Jawa Raden Mas Suryodilogo, adalah seorang panglima perang Kerajaan Mataram yang meninggalkan tana Jawa karena kalah dalam peperangan melawan tentara Belanda pada tahun 1628-1629 (Razak, 1982: 89). Ia bersama dengan gurunya Sayyid Zakaria, berangkat dari pelabuhan Gresik dan terus langsung ke Pamboang (Mandar). Sesampai di Tanah Mandar, mereka diterima dengan baik oleh raja Kerajaan Banggae, Topeanani Toniboseng (Mara'dia VI), dan bahkan raja pun memeluk agama Islam, dan ketika wafat diberi gelar To Matindo di Agamana (Sinrang, 1980: 101).

Mengenai kedatangan Sayyid Zakaria sebagai guru yang menyertai Suryodilogo dalam menyebarkan Islam di Pamboang, menurut ceritera masyarakat setempat (Rahman, wawancara, 23/7/2011), mengatakan bahwa beliau merupakan asal suku bangsa Arab dari Yaman. Beliau datang ke Sumatera (Aceh) bersama dengan pedagangpedagang Arab dan sekaligus sebagai penganjur agama Islam. Beliau kemudian melanjutkan perjalanan keJawa Timur setelah berdirinya Kerajaan Demak, dan disinilah beliau berkenalan dengan Raden Mas Suryodilogo dan mengangkatnya sebagai murid setia. Bertahun-tahun jalinan hubungan ini berlangsung barulah mereka meninggalkan Pulau Jawa menuju Sulawesi, yaitu setelah Suryodilogo kalah dalam peperangan melawan penjajah. Jika dikatakan Sayyid Zakaria bangsa Arab dari Yaman memang ada kemungkinan, sebab pada saatsaat pertama tersebarnya agama Islam ke Timur, pelabuhan Yaman memegang peranan penting dalam bidang perdagangan dan penyebaran agama Islam pada masa itu. Nama lengkap penganjur Islam dan sekaligus guru dari Suryodilogo, adalah Sayyid Zakaria Al-Yamanl Kata Al-Yamani (Sinrang, 1980: 15).

Ada beberapa versi tentang masuknya agama Islam ke Kerajaan Pamboang (Mandar), versi pertama mengatakan pada tahun 1592 yang dibawah oleh Raden Mas Suryodilogo. Versi lain mengatakan bahwa agama Islam masuk ke Kerajaan Pamboang dibawah oleh Sayyid Zakaria dan Raden Mas Suryodilogo pada awal abad ke-17 M, yaitu pada tahun 1604. Versi Lontaraq Mandar mengatakan bahwa agama Islam masuk ke Kerajaan Pamboang pada pertengahan abad ke-17 M, yaitu pada tahun 1665. Lontaraq Mandar milik Pak Ledang, berisi keterangan: ... apaq masae-masae i lao polemi i puang di Soba membawa assalangang siola Kapuang Jawa annaq saliangmo tau di Mandar di taung 1665, artinya: "menjelang beberapa waktu lamanya datanglah puang di Soba membawa agama Islam bersama kapuang Jawa, kemudian Islamlah orang Mandar pada tahun 1665". Apabila dilihat dari penyesuaian tahun, yaitu antara raja yang berkuasa di Mandar pada masa itu dengan membandingkan raja yang berkuasa ketika Islam masuk di Kerjaan Gowa. Raja Kerajaan Balanipa pada masa itu adalah Tomatindo di Langgana semasa dengan masa pemerintahan Sultan Hasanuddin di Gowa, yaitu pada tahun 16331669. Semasa pula dengan raja Kerajaan Pamboang Tomatindo di Agamana, berarti agama Islam datang di Pamboang antara tahun 1953-1669, atau masa terakhir dari masa pemerintahan Tomatindo di Agamana sekitar tahun 1665. 
Proses masuknya agama Islam di kawasanMandar jika dibandingkan dengan kawasan etnik Bugis, tampaknya memiliki perbedaan. Jika di kawasan etnik Bugis, proses masuknya agama Islam mendapat banyak tantangan yang hebat, namun tidak demikian halnya di daerah Mandar. Kerajaan Gowa sebagai penyebar agama Islam secara resmi kepada kerajaan-kerajaan yang ada di kawasan Sulawesi Selatan, menempuh cara damai dan peperangan. Kepada beberapa kerajaan di kawasan Bugis, seperti Kerajaan Soppeng, Wajo dan Bone, penyebaran agama Islam oleh Kerajaan Gowa dengan cara peperangan, sedangkan kepada beberapa kerajaan kecil lainnya, seperti kerajaankerajaan di Mandar, penyebaran agama Islam oleh Kerajaan Gowa berlangsung secara damai. Hal ini disebabkan karena kerajaan-kerajaan kecil tidak mungkin untuk melawan kekuatan Kerajaan Gowa yang memiliki tentara angkatan laut yang besar dengan ribuan prajurit. Selain itu, letak geografi Mandar yang sangat strategis memungkinkan daerah ini mendapat banyak pengaruh yang besar dari luar.

Setelah Islam diterima di kawasan Mandar, maka agama Islam berkembang dengan pesat, melaui cara-cara penyebaran Islam dengan melalui peranan golongan bangsawan, perkawinan, pendidikan dan budaya. Setelah Kerajaan Balanipa menerima agama Islam secara resmi, maka Kerajaan Gowa mengirim Abdurrahim Kamaruddin untuk mengajarkan agama Islam di kawasan tersebut. Hal ini terjadi karena sebelumnya hubungan baik yang telah terbina antar Balanipa dengan Gowa, sehingga Abdurrahim Kamaluddin dalam waktu yang relatif singkat, telah mengislamkan Maraqdia Pallis Kanna Cunang, dan dialah pemeluk agama Islam pertama di Tanah Mandar. Selanjutnya menyusul raja Kerajaan Balanipa Daetta Tommuane memeluk agama Islam pula (Razak, 1982: 104-105). Dengan memeluk agama Islam Mara'dia Bala'nipa, maka dalam waktu singkat sebagian besar rakyat di Kerajaan Balanipa telah menganut agama Islam, yaitu dengan mengikuti rajanya. Saluran Islamisasi melalui golongan bangsawan atau raja tidak hanya berlangsung di Kerajaan Bala'nipa, tetapi juga di kerajaan-kerajaan lainnya di daerah Mandar, seperti pada Kerajaan Pamboang. Setelah Raden Mas Suryodilogo dan Sayyid Zakaria berhasil mengislamkan Maraqdia Pamboang, Tomatindo di Agamana, maka keduanya dengan mudah pula menyebarkan Islam di wilayah Kerajaan Pamboang, bahkan sampai di Kerajaan Sendana, Tappalang dan Mamuju (Sewang, 2005:
34). Dalam beberapa segi kehidupan masyarakat, baik di bidang politik, pemerintahan, kehidupan sosial, dan seni budaya, turut pula mengalami perubahan akibat dari pengaruh agama Islam. Penerimaan agama Islam melalui golongan raja-raja atau bangsawan memungkinkan proses Islamisai lebih cepat daripada melalui golongan akar rumput. Hal itu di sebabkan masih adanya pandangan dari golongan masyarakat akar rumput di Indonesia terhadap rajanya atau golongan bangsawan secara kharismatik meskipun agama Islam tidak mengenal anggapan demikian (Tjandrasasmita, 1977: 116).

Salah satu saluran proses Islamisasi adalah, melalui lajur perkawinan. Ikatan perkawinan itu sendiri adalah merupakan suatu ikatan lahir dan batin, tempat menerima kedamaian di antara kedua individu. Kedua individu ialah suamiistri membentuk masyarakat justru menjadi inti dalam keluarga dan masyarakat. Kemudian dari perkawinan itu membentuk pertalian kekerabatan yang lebih besar di antara dua keluarga, baik dari keluarga laki-laki (suami) maupun dari pihak keluarga perempuan (isteri). Saluran Islamisasi dengan perkawinan itu akan lebih menguntungkan lagi bila terjadi antara seorang ulama dengan anak seorang bangsawan atau anak seorang raja, karena status sosial politik mereka turut mempercepat proses Islamisasi. Hal ini telah ditempuh oleh Abdurrahim Kamaluddin dalam mengembangkan Islam di daerah Mandar, beliau menikah dengan putri bangsawan Mara'dia Lembang. Demikian pula penyebar Islam lainnya di kawasan Pamboang, yaitu Raden Mas Suryodilogo menikah dengan I Lissi Puang putri Mara'dia Pamboang, dan Zayyid Zakaria menikah dengan Puanna Ibodi, putri Tomatindo di Agamana.

Saluran Islamisasi di samping melalui saluran kekuasaan para bangsawan dan perkawinan, dapat pula melaui saluran pendidikan. Abdurrahim Kamaluddin dalam usahanya menyebarluaskan agama Islam di Tanah Mandar, beliau juga mendirikan semacam kompleks pendidikan atau pesantren yang bernama Pasantren Mukmim. Ini adalah pendidikan pertama yang dikenal dalam sejarah Mandar, yang dapat menampung sekitar 44 orang pemuda sebagai murid guna dididik dan dijadikan kader Islam pada masa itu. Pembinaan kompleks pendidikan ini mendapat bantuan sepenuhnya dari Mara'dia Balanipa, Daetta Tommuane (Sewang, 1980: 36-37; Hamsah, 1976: 27). 
Penyebar agama Islam yang datang setelah Abdurrahim Kamaluddin, melanjutkan usahanya dalam bidang pendidikan agama Islam yang umumnya bersifat mistik, antara lain seperti ajaran Syekh Abdul Mannan alias Tuan di Salabose, Tuan Langngaran alias Tosalama di Labuang Padang, Tuan di Tonase, Tuan di Bulo-Bulo, yang menyebarkan Islam di Daerah Mambi, dan Tomatindo di Barana, yang menyebarkan agama Islam di Campalagian. Penyebaran Islam dengan metode mistik adalah lebih muda diterima oleh masyarakat yang masih tradisional, karena kaum sufi lebih toleran kebiasaan-kebiasaan ataupun adat istiadat yang dianut oleh masyarakat. Karena itu kaum sufi mempunyai peranan penting dalam Islamisasi pertama di kawasan Mandar (Hamsah, 1976: 27).

Di kawasan Mandar, pendidikan fiqih mulai dipopulerkan pada akhir abad ke-18 M oleh seorang guru yang bernama $\mathrm{H}$. Nuh alias $\mathrm{H}$. Toa, yang berpusat di Pambusuang kemudian di Campalagian. Kawasan Campalagian pernah menjadi pusat pendidikan (pesantren) Islam Mandar. Berkat jasa dalam bidang pendidikan dan guna mengenang beliau, maka didirikanlah sebuah pesantren bernama: Yayasan Pesantren Nuhiyah, pada tanggal 9 Juni 1968, dan berpusat di Pambusuang, Polewali Mandar. Dalam proses selanjutnya, ketika agama Islam telah menjadi panutan masyarakat tempatan, maka terjadilah proses budaya yang disebut akulturasi, yaitu akulturasi antara antara unsur budaya pra Islam dengan unsur budaya Islam, yang melahirkan unsur-unsur budaya baru. Unsurunsur budaya baru tersebut, tampak dalam pelbagai aspek kehidupan masyarakat lokal, baik dari segi keagamaan, politik, pemerintahan, ekonomi, maupun seni budaya. Dalam bidang keagamaan munculnya kepercayaan kepada Tuhan yang maha esa, dalam pemerintahan dengan munculnya Qadhi atau Kali (Mara'dia Sara'), Imang, Katte', Bidal dan Doya (Hamsah, 1976: 27-28; Sewang, 2005: 40). Dalam seni budaya dan kepercayaan, muncul suatu perayaan keagamaan yang disebut Maulu' Lompoa yang dirayakan secara besar-besaran yang berpusat di Masjid Tua Salabose dan Makam Syeh Abdul Mannan.

\section{Deskripsi Kompleks Makam Lombeng Susu}

Kompleks makam tersebut berada di Kampung Ajulita, Kelurahan Tande, Kecamatan Banggae Timur, Kabupaten Majene, Provinsi Sulawesi Barat, dengan titik koordinat S03 ${ }^{\circ} 30^{\prime} 49.7^{\prime \prime}, \mathrm{T}_{118^{\circ}} 58^{\prime} .28 .3^{\prime \prime}$, berada pada puncak bukit dengan ketinggian $176 \mathrm{~m}$ di atas permukaan laut. Di sekitarnya terdapat kebun penduduk lokal, dapat dicapai dengan naik kereta dan berjalan kaki sejauh $800 \mathrm{~m}$. Kompleks Makam Lombeng susu disebut oleh masyarakat lokal (Abdul Malik, wawancara, tanggal 22 Juni 2011) yang disebut kuburu limassusung (makam yang bersusun lima), khasnya makam yang digunakan oleh tokoh utama yang bergelar Lombeng Susu (orang yang panjang buah dadanya). Tokoh yang dimakamkan di makam yang paling besar tersebut adalah Pappuangan Tande (raja Kerajaan Tande) pertama yang bernama I Pura Para'bue. Kerajaan Tande adalah salah satu kerajaan kecil yang bergabung membentuk federasi menjadi Kerajaan Banggae dan telah memeluk agama Islam sekitar tahun 1700an.

\section{Bentuk Jirat Makam}

Pada situs makam tersebut ditemukan makam sebanyak 256 buah yang masih dapat dikenali, secara teknologi dan tipologi sama dengan jenis makam di situs Ondongan, yang membedakannya adalah makam yang dibuat dari blok-blok batu, tidak menggunakan tiang pada keempat sudutnya sebagai pengikat susunan blok batu, tetapi antara blok batu diikat saling terkait dengan teknik pasak. Makam berjejer dari arah utara ke selatan dengan tata letak adalah makam kategori ukuran besar dan sedang berada di tengah-tengah dan dikelilingi oleh makam kategori ukuran kecil. Hal yang menarik, adalah bahwa hampir semua makam yang terdapat di situs tersebut menggunakan jirat jenis teras berundak (D) sebanyak 244 buah, yang dibuat dari blok batu atau batu massif, dari ukuran besar hingga ukuran terkecil (misalnya makam berteras tiga dengan ukuran panjang hanya $35 \mathrm{~cm}$, lebar $20 \mathrm{~cm}$, tinggi $23 \mathrm{~cm}$ ). Terdapat juga sedikit makam jenis peti batu (F) sebanyak 12 buah makam. 
Gambar 1

Keadaan situs Kompleks Makam Lombeng Susu

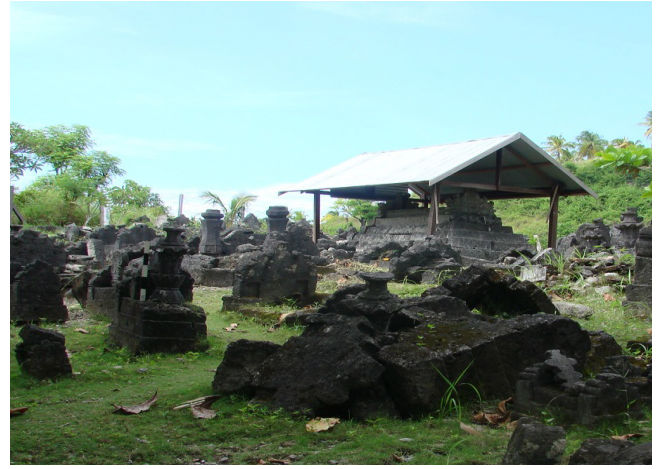

Sumber: Dokumentasi Rosmawati

Gambar 2

Jirat dan hiasan kepala kerbau makam pada Situs Lombeng Susu
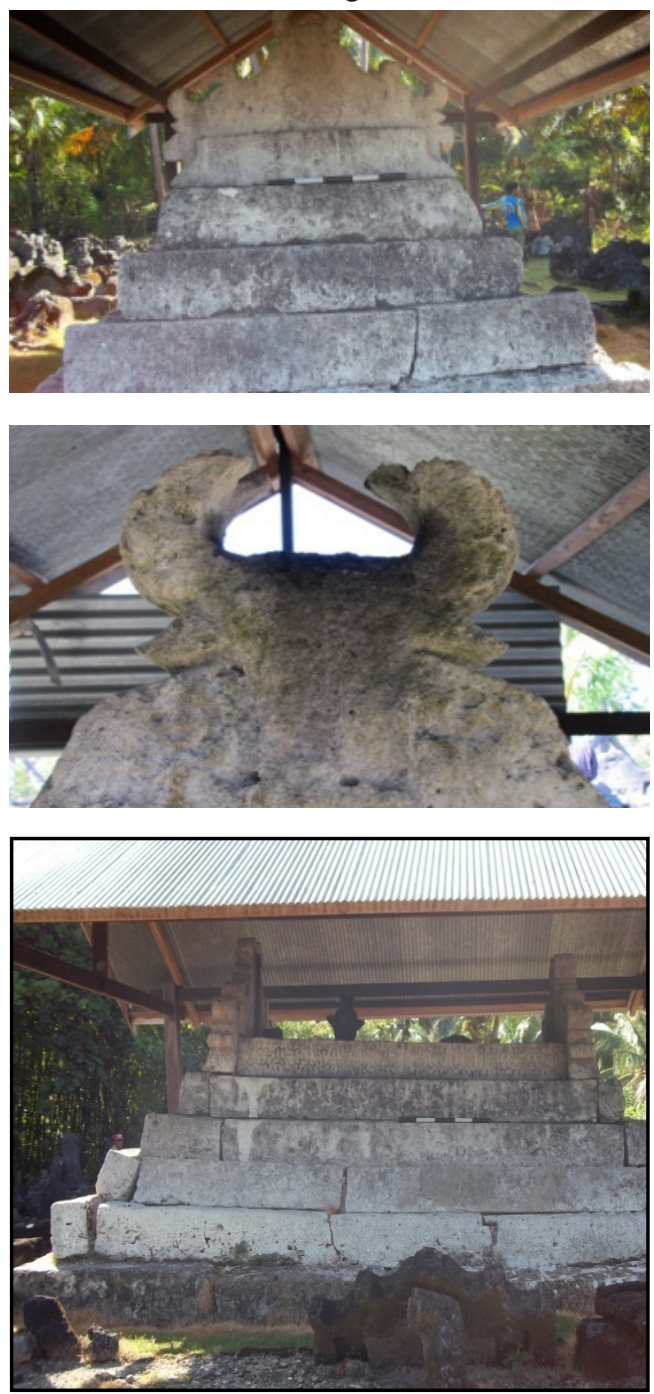

Sumber: Dokumentasi Rosmawat

Berikut uraian jenis jirat dan beberapa jenis nisan makam pada situs tersebut:
1. Jenis jirat makam teras berundak (D) sebanyak 244, yaitu makam kategori ukuran besar sebanyak 1 buah, kategori ukuran sedang 47 buah dan kategori ukuran kecil sebanyak 196 buah. Makam dibuat dari susunan blok batu karang dengan teknik pasak dan susun timbun khasnya pada makam berundak kategori besar dan sedang atau dari satu bongkahan batu massif khasnya pada makam berundak kategori sedang dan kecil. Pada sisi utara dan selatan terdapat gunungan dan di atasnya ditancapkan satu atau dua buah nisan. (1) Makam kategori besar yaitu makam I Pura Para’bue (Lombeng Susu) bersama isterinya sebagai makam utama, dibuat dari susunan blok batu yang berteras lima, dengan ukuran panjang panjang dasar 380 $\mathrm{cm}$, panjang puncak $220 \mathrm{~cm}$, lebar dasar $230 \mathrm{~cm}$, lebar puncak $110 \mathrm{~cm}$ dengan tinggi keseluruhan $215 \mathrm{~cm}$. Papan batu teras lima dihiasi dengan motif suluran daun, pada sisi utara dan selatan terdapat gunungan bersayap dan bertangkai menyerupai tanduk kerbau, dengan hiasan motif suluran daun, bunga dan kepala kerbau. Terdapat empat buah nisan, yaitu nisan sisi utara adalah jenis mahkota-silindrik dan sisi selatan adalah nisan jenis hulu badik dan

\section{Gambar 3}

Makam kategori sedang, berteras lima dan tiga, dibuat dari batu massif dan blok batu di situs

$$
\text { Kompleks Makam Lombeng Susu }
$$
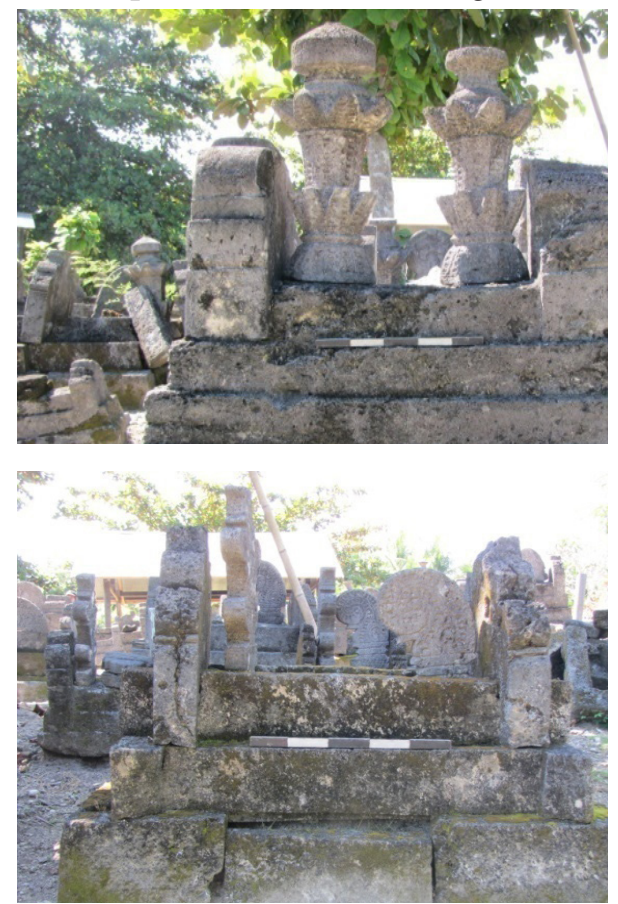

Sumber: Dokumentasi Rosmawati 
Gambar 4

Makam teras berundak kategori kecil berundak lima dan tiga dari batu massif di situs Kompleks Makam Lombeng Susu
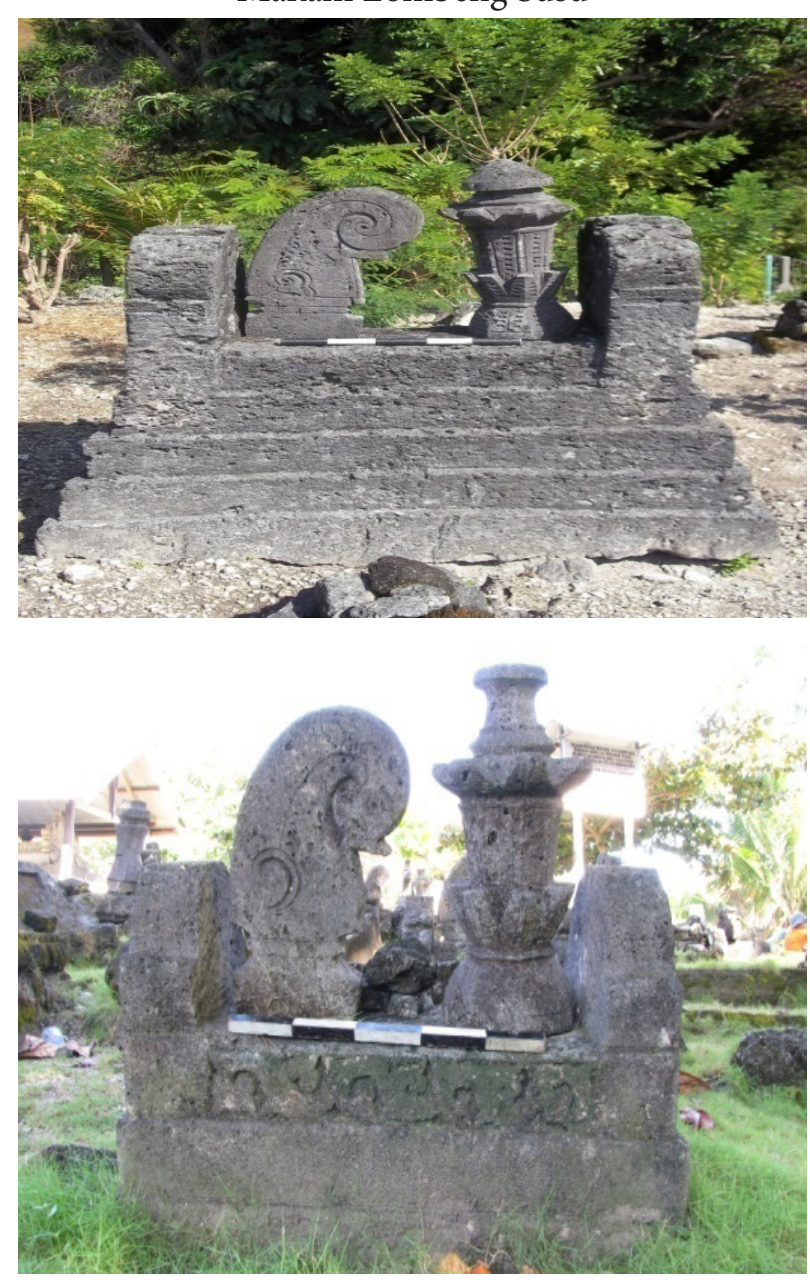

Sumber: Dokumentasi Rosmawati

pedang bertanduk, semuanya dibuat dari batu karang dan menggunakan lapik, nisan jenis mahkota dan hulu badik berhiaskan motif suluran daun. (2) Makam kategori sedang, dibuat dari blok batu dan batu massif, berteras tiga hingga lima, terdapat gunungan dan nisan berhias suluran daun atau polos. Ukuran jirat makam adalah panjang antara $280-125 \mathrm{~cm}$, lebar antara $115-53 \mathrm{~cm}$ dan tinggi $165-78 \mathrm{~cm}$. Ukuran contoh makam adalah panjang $200 \mathrm{~cm}$, lebar $112 \mathrm{~cm}$ dan tinggi $106 \mathrm{~cm}$. (3) Makam kategori kecil, dibuat dari satu bongkahan batu massif, gunungan dan nisan kadang-kadang berhias motif suluran daun. Ukuran jirat makam adalah panjang antara $115-35 \mathrm{~cm}$, lebar antara 60-20 $\mathrm{cm}$, tinggi antara $87-23 \mathrm{~cm}$, contoh ukuran makam adalah panjang $80 \mathrm{~cm}$, lebar $43 \mathrm{~cm}$ dan tinggi $60 \mathrm{~cm}$.
Gambar 5

Bandingkan jirat makam dari ukuran sedang hingga yang terkecil

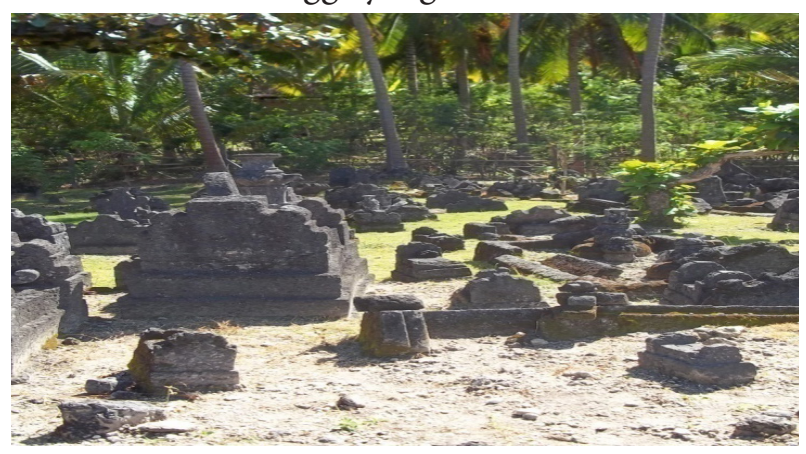

Sumber: Dokumentasi Rosmawati

2. Jenis jirat makam peti batu $(G)$ sebanyak 12 buah, yaitu makam yang hanya terdiri dari subasemen dari susunan blok batu dan batu gunung, di atasnya ditancapkan satu atau dua buah nisan, makam jenis ini sebanyak 21 buah.

\section{Jenis Nisan Makam}

Banyak makam yang terdapat di situs tersebut yang sudah tidak ada nisannya, namun bekas berupa lapik masih tersisa, sehingga diketahui bahwa semua makam menggunakan 2 buah nisan yang saling berpasangan. Jumlah nisan yang ditemukan sebanyak 200 buah, berdasarkan klasifikasi Rosmawati (2008, 2011), terdiri dari nisan jenis pedang (A5) sebanyak 40 buah, hulu badik (C) sebanyak 68 buah, mahkota $(\mathrm{E})$ sebanyak 80 buah, phallus $(\mathrm{G})$ sebanyak tiga buah dan silindrik (I3) sebanyak 5 buah. (1) Nisan jenis pedang hanya terdiri dari varian A5 yang bertangkai satu atau dua susun menyerupai tanduk kerbau, dibuat dari batu karang dengan variasi ukuran, ada yang polos dan ada berhias suluran daun.

Ukuran tinggi antara 76-27 cm, lebar badan antara 38-13 cm dan tebal antara $4-11 \mathrm{~cm}$, ukuran nisan contoh adalah tinggi $65 \mathrm{~cm}$, lebar $31 \mathrm{~cm}$ dan tebal $10 \mathrm{~cm}$. (2) Nisan jenis hulu badik (C) dibuat dari batu karang dengan ukuran bervariasi, ada yang polos dan ada berhias suluran daun. Ukuran tinggi antara $75-24 \mathrm{~cm}$, lebar badan antara $32-11$ $\mathrm{cm}$, tebal antara 4-11 cm, ukuran nisan contoh adalah tinggi $57 \mathrm{~cm}$, lebar badan $22 \mathrm{~cm}$ dan tebal $9 \mathrm{~cm}$. (3) Nisan jenis mahkota (E) dibuat dari batu karang dengan ukuran agak bervariasi, ada yang polos dan ada berhias suluran daun dan geometri. 
Ukuran tinggi antara 78-18 $\mathrm{cm}$ dan diameter badan antara $36-8 \mathrm{~cm}$, ukuran nisan contoh adalah tinggi $63 \mathrm{~cm}$ dan diameter $24 \mathrm{~cm}$. (4) Nisan jenis phallus (G) badan bersisi delapan dan kepala berbentuk kelamin laki-laki, dibuat dari batu karang dan tidak berhias, ukuran adalah tinggi $75 \mathrm{~cm}$ dan diameter $32 \mathrm{~cm}$. (5) Nisan jenis silindrik semuanya varian I3, bersisi delapan dengan kepala berbentuk prisma dan bulatan dan tidak berhias. Ukuran tinggi antara 81$55 \mathrm{~cm}$ dan diameter badan antara $33-13 \mathrm{~cm}$, ukuran nisan contoh adalah tinggi $78 \mathrm{~cm}$ dan diameter 28 $\mathrm{cm}$.

Nisan pada situs makam tersebut semuanya berpasangan dua buah untuk makam satu jenazah dan empat buah untuk makam dua jenazah. Nisan jenis mahkota dan hulu badik, berpasangan dengan semua jenis nisan lainnya, seperti nisan mahkota berpasangan dengan nisan mahkota, hulu badik, pedang bertanduk, phallus, silindrik dan nisan hulu badik berpasangan dengan mahkota, pedang bertanduk, phallus, silindrik. Dengan demikian nisan jenis mahkota dan hulu badik tidak menyimbolkan jenis kelamin, melainkan menyimbolkan status atau peranan, sedangkan nisan jenis pedang bertangkai menyimbolkan perempuan dan nisan jenis phallus dan silindrik menyimbolkan laki-laki. Nisan jenis mahkota menyimbolkan bangsawan dan jenis hulu badik menyimbolkan keberanian. Dengan demikian, pasangan nisan mahkota-mahkota menyimbolkan bangsawan tinggi, mahkota-hulu badik menyimbolkan bangsawan pemberani, mahkota-pedang bertanduk menyimbolkan bangsawan perempuan, mahkotasilindrik menyimbolkan bangsawan lelaki, hulu badik-pedang bertangkai menyimbolkan perempuan pemberani, hulu badik-phallus dan silindrik menyimbolkan laki-laki pemberani.

\section{Gambar 6}

Nisan jenis pedang tanduk (A5), hulu badik dan mahkota di situs Kompleks Makam Lombeng Susu
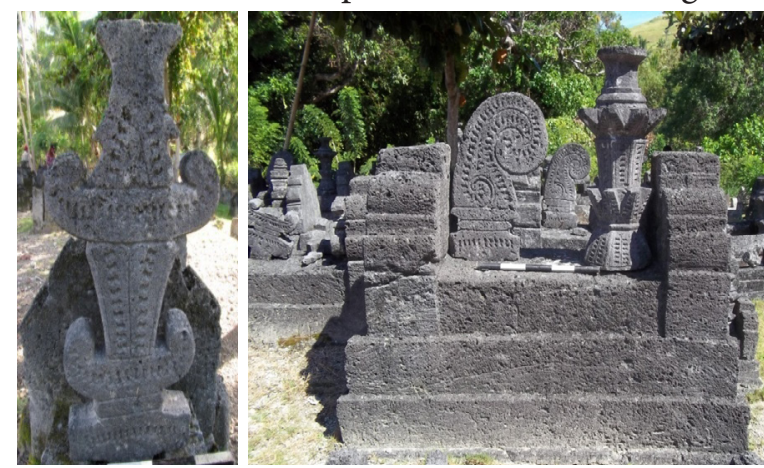

Sumber: Dokumentasi Rosmawati
Gambar 7

Pasangan nisan pada makam dan ukuran nisan terkecil di situs Kompleks Makam Lombeng Susu
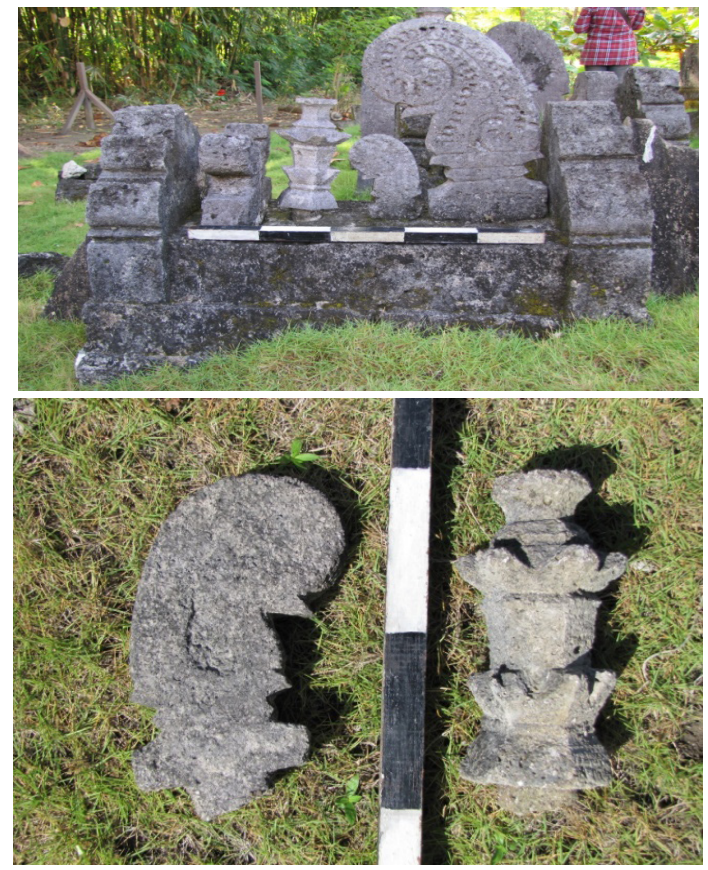

Sumber: Dokumentasi Rosmawati

Gambar 8

Jenis nisan phallus dan silindrik di situs Kompleks

Makam Lombeng Susu
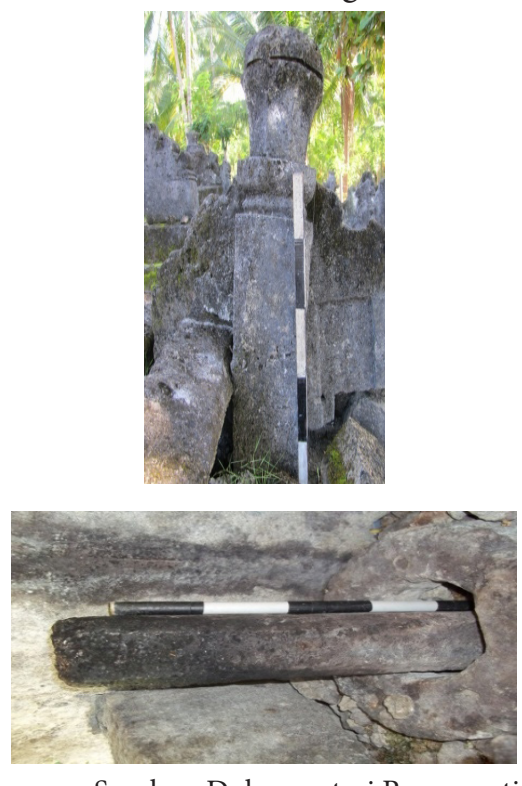

Sumber: Dokumentasi Rosmawati

\section{PENUTUP}

Masuk dan berkembangnya Islam di kawasan Mandar membawa perubahan-perubahan dalam berbagai aspek kehidupan masyarakat. Tempat-tempat pemujaan megalitik, pembakaran mayat, penguburan yang berlangsung lama tidak 
dilaksanakan lagi, tetapi kemudian muncul masjid, surau dan makam. Sistem kasta di dalam masyarakat dihapus, patung manusia dewa-dewa serta bentukbentuk zoomorphic tidak lagi dibuat.Para seniman ukir kemudian menekuni pembuatan kaligrafi, mengembangkan ragam hias flora dan geometris, serta melahirkan ragam hias stiliran. Akan tetapi pada sisi lain budaya tidak dapat dikotakkotakkan, sehingga terjadi pula kesinambungankesinambungan yang inovatif sifatnya. Masjid dan cungkup makam mengambil bentuk atap tumpang dan teras berundak yang bentuk dasarnya sudah dikenal pada masa sebelumnya sebagaimana tampak pada beberapa makam pra Islam, misalnya di Enrekang (Duli, 2013), Mamasa (Duli, 2014), dan Toraja (Duli, 2015). Bangunan makam Islam merupakan hal baru di Indonesia kala itu, olehnya itu terciptalah nisan dan jirat dalam berbagai bentuk karya seni sesuai dengan geografi budayanya masing-masing (Rosmawati, 2011 dan 2012).

Di kawasan Mandar, berkembang karya seni makam secara khas sesuai dengan budaya yang telah dikenal sebelumnya.Jirat makam dibentuk berteras secara lurus dengan meniru konstruksi rumah bertiang, yaitu pada setiap sudut jirat makam terdapat tiang yang berfungsi sebagai pengikat balok batu yang dipasang dengan teknik pasak. Bentuknisan khas Mandar yang berkembang adalah nisan tipe hulu badik, mahkota dan pedang bertangkai. Ornamen yang digunakan adalah motif geometri dengan suluran daun dan bunga yang mencerminkan alam sekitar (Duli et al, 2013 dan 2014).Bahan yang digunakan adalah jenis batu karang yang banyak terdapat di kawasan tersebut.

Oleh karena budaya Islam di kawasan Mandar dibawa oleh para pendatang dari Melayu, Jawa dan Makassar, menyebabkan terjadinya akulturasi budaya. Akulturasi tersebut terjadi karena ada kontak dengan kebudayaan lain, atau dengan kata lain karena ada kekuatan dari luar (Rosmawati, 2013). Pertemuan dan akulturasi antara kebudayaan prasejarah, Islam dan bahkan kemudian juga kebudayaan Barat, terjadi dalam jangka waktu yang panjang dan bertahap. Hasil akulturasi menunjukkan bahwa Islam memperkaya kebudayaan yang sudah ada dengan menunjukkan kesinambungan budaya, namun tetap dengan ciri-ciri tersendiri.

Masuknya pengaruh budaya Islam tidak menghilangkan identitas budaya lokal. Budaya praIslam tetap berlanjut, seperti jirat teras berundak, gunungan, peti batu dan nisan menhir. Terjadi perpaduan budaya yang merupakan buah dari sikap adaptif dari penduduk setempat terhadap budaya asing yang masuk. Kendati terjadi perubahan budaya namun tidak sampai mengubah esensi dan nilai yang dikandungnya. Dengan demikian tidak terjadi konflik antara budaya yang bertemu. Hal itu dapat mengakibatkan terjadinya akulturasi budaya, yang akhirnya menghasilkan bentuk baru berupa budaya Islam yang mengalami perlembangan dari masa ke masa. Akulturasi budaya hadir pada komponen arsitektur makam meliputi tata letak, bentuk jirat dan nisan.

\section{UCAPAN TERIMA KASIH}

Tulisan ini hadir di hadapan pembaca berkat bantuan para penelaah yang telah memberikan review atas perbaikan artikel ini, pada kesempatan ini kami ucapkan terima kasih kepada Prof. Dr. Stephen Chia, Prof. Dr. Akin Duli, MA, Muhammad Nur, Mohd. Minsya Baharuddin, Yohanis Kasmin, Dedy dan semua yang membantu. Kepada Universiti Penyelidikan dan Kementerian Pendidikan Tinggi Malaysia, USM, Pulau Pinang, atas bantuan dana dalam melaksanakan penelitian ini kami ucapkan terima kasih, serta kepada pemerintah setempat yang turut mendukung penelitian ini. Ucapan terima kasih pula kami ucapkan kepada temanteman yang membantu dalam penelitian ini.

\section{DAFTAR PUSTAKA}

Duli, Akin et al. 2013. Monumen Islam di Sulawesi Selatan. Makassar: Identitas Universitas Hasanuddin. . 2013. "The Mandu Coffin: A Boat Syimbol of Ancestral Spirits Among the Enrekang People of South Sulawesi". Journal RIMA (Review of Indonesian and Malaysian Affairs), Vol 47, No. 1,2013. Camberra: Australian National University and University of New South Wales, Australian Defence Force Academy. 2014. Monumen Islam di Sulawesi Barat. Makassar: BPCB Makassar.

2014. "Shape and Chronology of Wooden Coffins in Mamasa, West Sulawesi, Indonesia" dalam Tawarikh, International Journal for Historical Studies, Vol. 5, No. 2, April 2014, Hal 177-186. Bandung: ASPENSI.

2015. "Typology and Chronology of Erong Woodenn Coffins in Tana Toraja, South Celebes", dalam Time and Mind, The Journal of Archaeology, Consciousnessand Culture, Vol. 8, No. 1, hal. 3-10, Januari 2015. London: Routledge, Taylor and Francis Group.

Hamsah, M.D. 1976."Abdul Rahim Kamaluddin Pelopor Penganjur Agama Islam di Daerah Mandar Sulawesi Selatan", dalam Panji Masyarakat, hal.27. Jakarta. 
Poelinggomang, E et al. 2004. Sejarah Sulawesi Selatan, Jld 1. Makassar: Badan Penelitian dan Pengembangan Daerah Propinsi Sulawesi Selatan.

Razak, S. 1982. "Tinjauan Historis Tentang Struktur Pemerintahan Kerajaan Pamboang dalam Hubungannya dengan Masuknya Islam” dalam Skripsi. Ujung Pandang: IAIN Alauddin.

Rosmawati. 2011. “Tipologi dan Perkembanagn Bentuk Jirat dan Nisan Makam Kuno di Sulawesi Selatan" dalam Jurnal Lensa Budaya, Vol. 5, No.3. Edisi Desember 2011.

2012. "Bentuk-Bentuk Peninggalan Budaya Islam di Kawasan Situs Tosora" dalam Buletin Somba Opu, Edisi Desember 2012. Makassar: Balai Pelestarian Peninggalan Purbakala Makassar. . 2013. "Perkembangan Tamadun Islam di
Sulawesi Selatan, Indonesia: Dari Perspektif Arkeologi dan Sejarah". Disertasi Doktoral. Pusat Penyelidikan Arkeologi Global (PPAG), Universiti Sains Malaysia-Pinang.

Sewang, M. Ahmad. 1980. "Peranan Qalam Dalam Pergerakan KRIS Muda di Daerah Mand ar”. Skripsi. Ujung Pandang : IAIN Alauddin. 2005. Islamisasi Kerajaan Gowa (Abad XVI Sampai Abad XVII). Jakarta: Yayasan Obor Indonesia.

Sinrang, S. 1980. Mengenai Mandar Sekilas Lintas. Ujung Pandang: Group Tipalaya Mandar.

Tjandrasasmita, U. 1977. Sejarah Nasional Indonesia, Jld. III. Jakarta: Balai Pustaka.

Zuhri, S. 1979. Sejarah Perkembangan Islam dalam Perkembangannya di Indonesia. Bandung: PT. AlMa'arif. 